\title{
MORFOLOGIA DE DEPRESSÕES FECHADAS EM DOMÍNIO CÁRSTICO-QUARTZÍTICO NA BACIA DO RIBEIRÃO SANTANA/MG: DATAÇÕES ABSOLUTAS INICIAIS ${ }^{1}$
}

\author{
Rogério Uagoda \\ Msc. e Doutorando (PPGG-UFRJ) e Pesquisador do GEOHECO/DEGEO/IGEO/UFRJ - Av. Athos da Silveira Ramos, 274 - \\ Ed. do CCMN - Bloco H - Sala H1-015 - Cidade Universitária -RJ- Cep 21941-916 - e-mail: uagoda@yahoo.com.br \\ Ana Luiza Coelho Netto \\ Professora Titular, Pesquisadora 1B-CNPq e Coordenadora do GEOHECO/DEGEO/IGEO/UFRJ - Av. Athos da Silveira Ramos, \\ 274 - Ed. do CCMN - Bloco H - Sala H1-015 - Cidade Universitária - Cep 21941-916 - e-mail: ananetto@acd.ufrj.br \\ André de Souza Avelar \\ Professor Adjunto e Vice-coordenador do GEOHECO/DEGEO/IGEO/UFRJ - Av. Athos da Silveira Ramos, 274 - Ed. do CCMN - \\ Bloco H - Sala H1-015 - Cidade Universitária - Cep 21941-916 - e-mail: andreavelar@acd.ufrj.br
}

\begin{abstract}
Resumo
Este trabalho objetiva classificar formas de depressões fechadas encontradas no médio-baixo vale do Ribeirão Santana e identificar a idade de depósitos orgânicos nas encostas e nos terraços fluviais. Busca-se entender a relação entre o aprofundamento de dolinas e a abertura de concavidades suspensas ou topograficamente ajustadas aos canais principais. Os resultados indicam quatro grupos de depressões, que podem demonstrar estágios evolutivos distintos, assim como o mapeamento de concavidades e depósitos de encostas. Datações absolutas apontam idades similares entre sedimentos no interior de depressões e nas concavidades estruturais suspensas, podendo demarcar evento de ajuste de nível de base com propagação regional.
\end{abstract}

Palavras-chave: depressões fechadas, concavidades, depósitos de encosta.

\begin{abstract}
The present research aims to classify closed depressions forms found in the lower middle valley of the Ribeirão Santana and to identify the age of organic deposits in hill slopes and fluvial terraces. The research goal is to understand the relationship between the lowered of dolines and the opening of concavities, suspended or topographically adjusted to the bottoms of the fluvial valleys. The results indicate four depressions groups that could demonstrate distinct evolutions stages, and geomorphological mapping of the concavities and the hill deposits. Absolute dating shown similar ages between sediments confined in the closed depressions and in the suspended concavities. These results would demonstrate a regional propagation of a knickpoint adjustment event.
\end{abstract}

Keywords: closed depressions, Hollows, hill slopes deposits.

\footnotetext{
${ }^{1}$ Agências Financiadoras: CNPq e FAPERJ.
} 


\section{Introdução}

Sistemas cársticos desenvolvidos em rochas não carbonáticas vem sendo descritos na literatura nacional e internacional. Estudos anteriores do GEOHECO-UFRJ mostraram haver um sistema cárstico em rochas quartzíticas na bacia do Ribeirão Santana/MG, afluente do Rio Preto (Avelar et al, 2006; Uagoda et.al, 2006; Uagoda, 2006; Uagoda et.al, 2008) - ver localização na Figura 1 . Na região aonde se insere a bacia em estudo ocorrem as litologias da sequência metassedimentar Andrelândia (Ribeiro et al., 1990; Heilbron et al., 1995), composta por biotita-gnaisses bandados e quartzitos, dobrados regionalmente e em afloramentos, oriundas de pelo menos três fases de deformação.

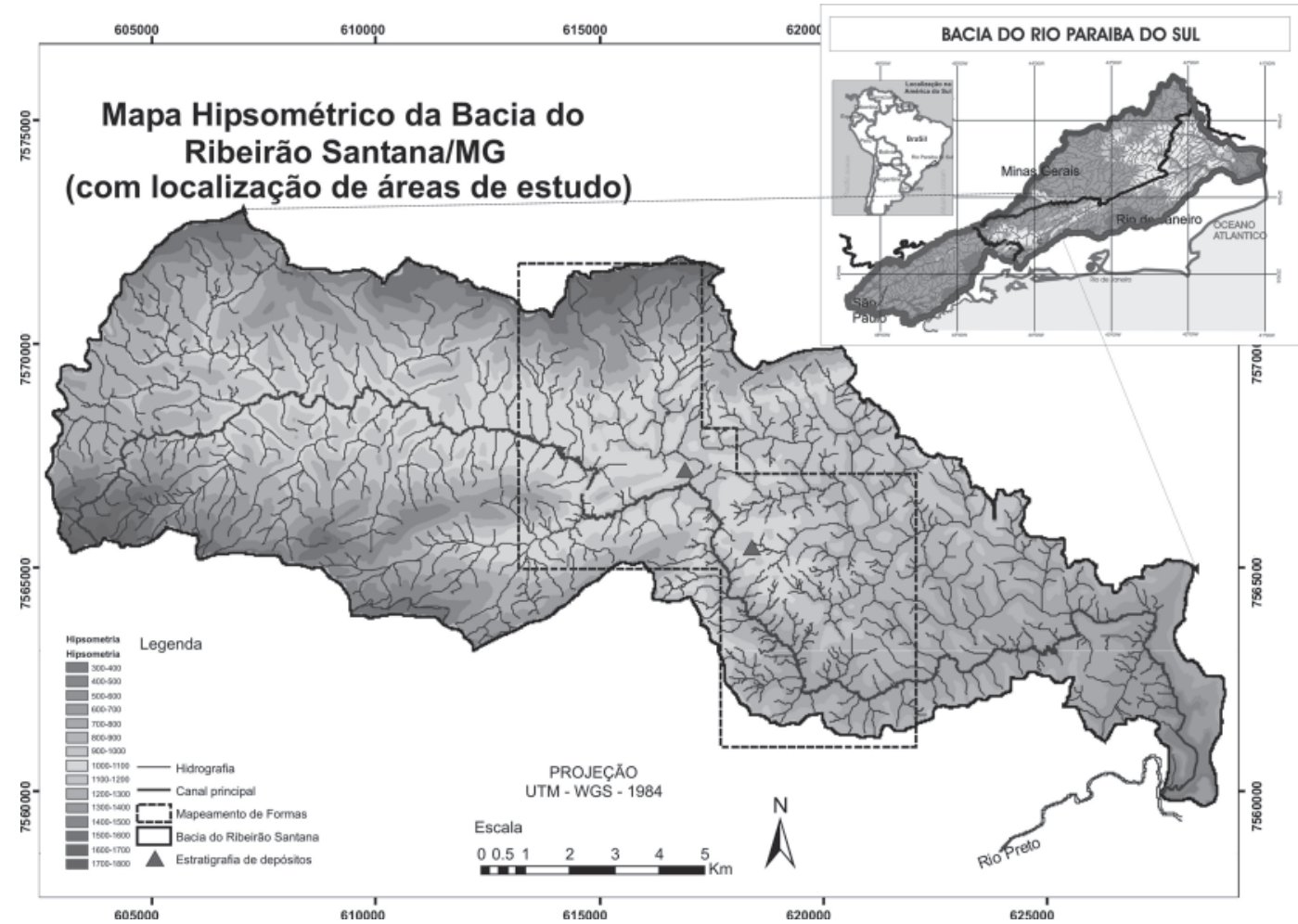

Figura 1 - Mapa hipsiométrico da bacia do Ribeirão Santana, com localização das áreas de mapeamento de formas e seções estratigráficas com datação. No canto superior direito: localização na bacia do rio Paraíba do Sul.

Avelar et al. (2006) ressaltam que na bacia em estudos o gnaisse é rico em biotita, quartzo, feldspato e granada, e por vezes, tem silimanita e turmalina, com foliação metamórfica bem marcada e granulometria entre 2 e $5 \mathrm{~mm}$. Os quartzitos foram observados em dois litotipos: (1) quartzito puro, com mais de $95 \%$ de quartzo, em cristais maiores, entre 3 e $8 \mathrm{~mm}$, com aspecto muito homogêneo, sacaroidal e foliação muito mal definida; (2) quartzito impuro, com quartzo associado ao feldspato e, por vezes, muscovita, apresentado granulometria mais fina, com grãos entre 1 e $3 \mathrm{~mm}$. Estratigraficamente, o gnaisse está na parte inferior da sequência, gradando para o quartzito impuro e, no topo, ao quartzito puro. Estes autores ressaltam que, devido ao dobramento deitado destas rochas, em vastas áreas os contatos e as foliações possuem mergulhos sub-horizontais, que, associado ao faturamento vertical (ou sub-vertical), permite a infiltração da água nos topos e exfiltração nos trechos médios das encostas. Esta percolação causa a dissolução do quartzo, feldspato e muscovita nos trechos de contato entre o quartzito puro (acima) e impuro (abaixo), formando cavernas por dissolução, de formato alongado, sem espeleotemas e orientadas pelo fraturamento.

Após a dissolução mineral, observa-se redução da coesão da rocha, favorecendo a atuação mecânica, através da queda de blocos e por fluxos d'água internos que transportam material clástico quartzoso para o sistema encosta-fluvial. Por vezes, a dissolução é seguida por subsidência ou colapso, formando depressões fechadas ou dolinas. Uagoda (2006) indica que as cavernas e feições de abatimento concentram-se nas áreas montanhosas quartzíticas enquanto as dolinas de dissolução (depressões fechadas), assim como as concavidades topográficas associadas à abertura destas dolinas, concentram-se nas áreas de encostas convexo-côncavas em substrato rochoso de biotita- 
gnaisse. Uagoda et al. (2006) estudando os depósitos sedimentares de encostas observaram a ocorrência de níveis orgânicos suspensos em cerca de sete metros, em relação ao nível atual do rio, apresentando níveis de intercalação entre deposição de encosta e camadas orgânicas em sua estratigrafia. Níveis hidromórficos e orgânicos confinados também foram encontrados nos depósitos de fundo de depressões fechadas e nas concavidades associadas à abertura destas depressões.

Quanto às depressões em divisores, feições que são amplamente distribuídas na bacia, Filizola \& Boulet (1996), em estudos na bacia sedimentar terciária de Taubaté (SP), assim como Castro e Coelho Netto (2002) e Coelho Netto (2003), em estudos na bacia do rio Bananal (SP/RJ), consideram que tais formas poderiam estar associadas a mecanismos de subsidência geoquímica favorecidos por fluxos d'água em fraturamentos das rochas e, ainda, que estas depressões poderiam abrir para originar os vales no domínio das encostas.

Neste trabalho busca-se uma primeira classificação das feições morfológicas associadas à evolução de depressões fechadas e, por sua influência, à abertura dos vales de cabeceiras ou concavidades estruturais, anteriormente definidas por Avelar e Coelho Netto (1992) e revisto por Coelho Netto (2003). Incluem-se ainda as primeiras datações absolutas dos depósitos associados à evolução de depressões fechadas ou de concavidades estruturais suspensas ou ajustadas topograficamente aos vales fluviais adjacentes.

\section{Materiais e métodos}

O mapeamento de feições cársticas foi realizado com levantamento de campo, restituição de fotografias aéreas 1:25.000 e plotagem em carta topográfica 1:10.000. Foram destacados alguns aspectos morfológicos das depressões fechadas e dos vales de cabeceiras, assim como os depósitos de encostas e fluviais. A classificação morfológica das concavidades estruturais foi uma adaptação do trabalho de Coelho Netto (2003).

Os levantamentos de solos foram realizados com auxilio de um trado manual de 5 metros de comprimento, com coletor de $25 \mathrm{~cm}$ de diâmetro, e uma carta de cores de solos (Munsell, 1971). A análise granulométrica seguiu as técnicas de laboratório preconizadas por Folk \& Ward (1957). Datações absolutas de matéria orgânica no solo foram obtidas com análises de ${ }^{14} \mathrm{C}$, realizadas no Radiation Hygiene Monitoring Laboratory, Kiev, Ucrânia, sob a responsabilidade do Dr. Michael Buzinny.

\section{Resultados}

Feições geomorfológicas características.

Em uma área de $56,32 \mathrm{~km}^{2}$ no interior da bacia em estudos (figura 1) foram identificadas 131 feições doliniformes (depressões fechadas), além de 281 concavidades topográficas (vales de cabeceiras) e 18 feições erosivas (tipo ravina), contidas na tabela 1 .

Tabela 1 - Ocorrência de feições doliniformes, concavidades e ravinas no interior da bacia.

\begin{tabular}{lll}
\hline Grupo & Descrição da Forma & No. de Ocorrências \\
\hline 1 & Depressões rasas em topos planos & 61 \\
2 & Depressões rasas em divisores rebaixados & 15 \\
3 & Depressões rasas em encostas & 26 \\
4 & Depressões profundas em encostas & 29 \\
5 & Concavidades suspensas & 221 \\
6 & Concavidades ajustadas & 60 \\
7 & Ravinas em encostas & 18 \\
\hline
\end{tabular}

Dentre as principais características das feições doliniformes (figura 2) podemos destacar: grupo 1 - depressões rasas em topos planos são relativas à dolinas de dissolução, sendo mais largas do que profundas, podendo indicar o início do processo de denudação química de uma cabeceira de drenagem; grupos 2 e 3 - depressões rasas em divisores rebaixados e depressões rasas em encostas, possuem rebaixamento de divisor em direção a concavidades abertas ou a canais erosivos adjacentes, podendo estar alimentando a rede de canais, mesmo que em subsuperfície; grupo 4 - depressões profundas em encostas diferem de todas as outras pelo fato de serem mais profundas do que largas e poderem ocorrer em qualquer posição da encosta, seja côncava ou conve$\mathrm{xa}$; parecem mais relacionadas às dolinas de abatimento.

No caso das concavidades topográficas ou vales de cabeceiras, foram encontradas, 221 concavidades topograficamente suspensas ( $31 \%$ da área total) e 60 concavidades topograficamente ajustadas ao canal coletor $(7,25 \%$ da área total). Vale dizer, que a densidade total de concavidades, $38,25 \%$, é superior a densidade total de concavidades encontrada nos estudos de Avelar \& Coelho Netto (1992), em diferentes locais da bacia do rio Bananal, com 18,2\% e 15\%, respectivamente; os autores inferem uma relação direta com a densidade de fraturas no meio rochoso. A densidade total de concavidades ainda é maior do que os valores descritos em diversos locais na bacia do rio Bananal e outras bacias adjacentes, por Oliveira \& Meis (1985), em torno de $29 \%$. Este fato, segundo Coelho Netto (2003) seria um reflexo do estágio evolutivo mais adiantado na bacia do rio Bananal do que na bacia em estudo. Em relação às ravinas, fica clara a pouca expressividade destas na área estudada, havendo um

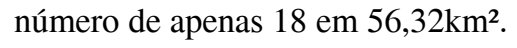


Uagoda, R. et al

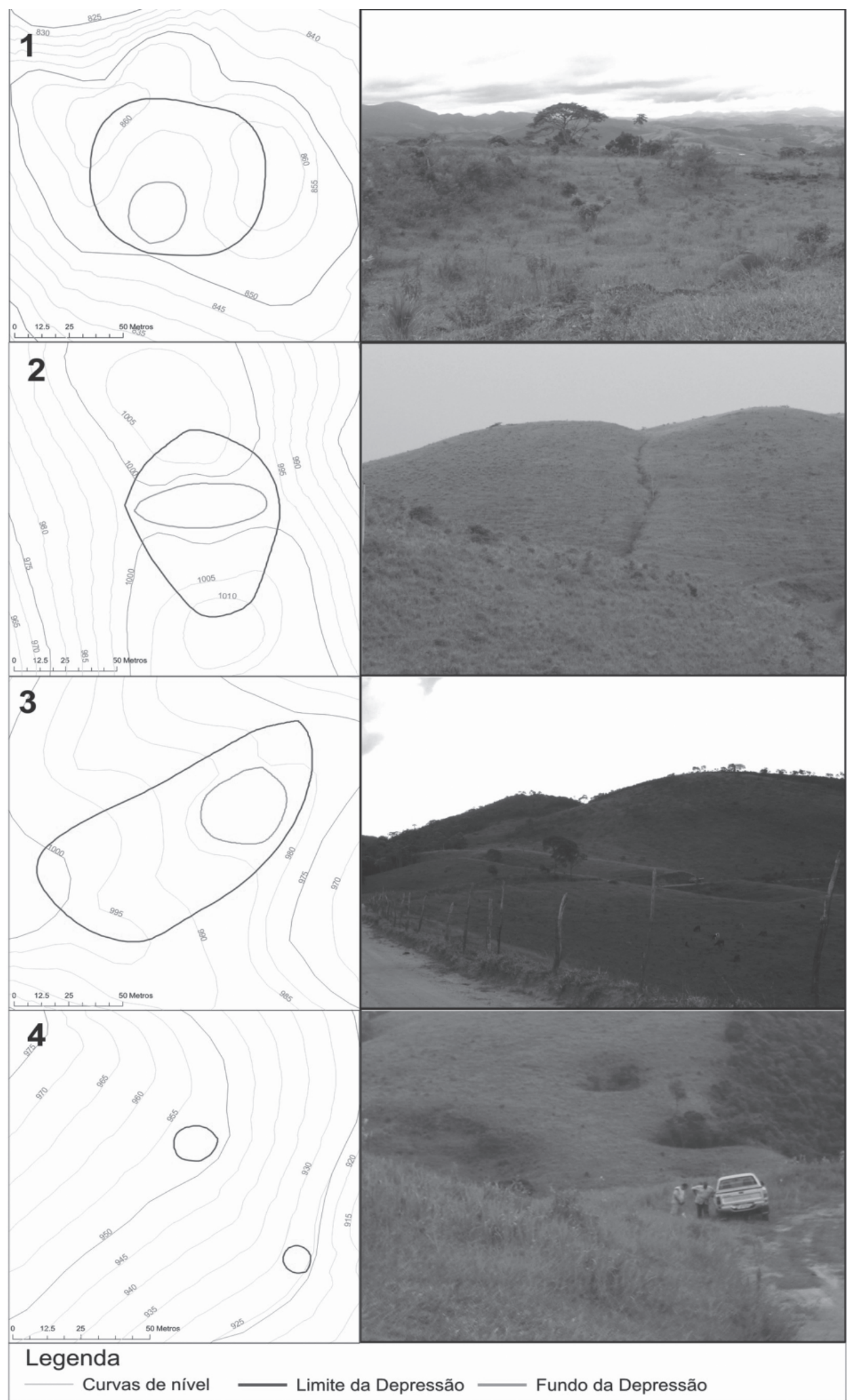

Figura 2 - Formas e fotos de depressões. 1. Depressões rasas em topos planos; 2. Depressões rasas em divisores rebaixados; 3. Depressões rasas em encostas; 4. Depressões profundas em encostas. 


\section{Depósitos de encostas}

A espacialização dos depósitos aqui identificados está bastante relacionada à distribuição de concavidades mapeadas (figura 3). No interior de depressões, onde é indicada a área de fundo de depressão, geralmente há acumulação de depósitos dos sedimentos erodidos de suas encostas laterais sobrepostos aos materiais intemperizados no seu interior. A mesma situação ocorre naquelas concavidades topografica- mente suspensas que são mais estreitas em sua base. No caso das concavidades topograficamente ajustadas ao fundo de vale adjacente, percebe-se a ocorrência de depósitos em forma de leques aluviais, ora com depósitos suspensos em relação ao nível de base atual (cerca de 7 metros, na maioria dos casos) ora com depósitos topograficamente ajustados a atual planície de inundação dos vales, que, na maioria dos casos, corresponde a uma área brejosa.

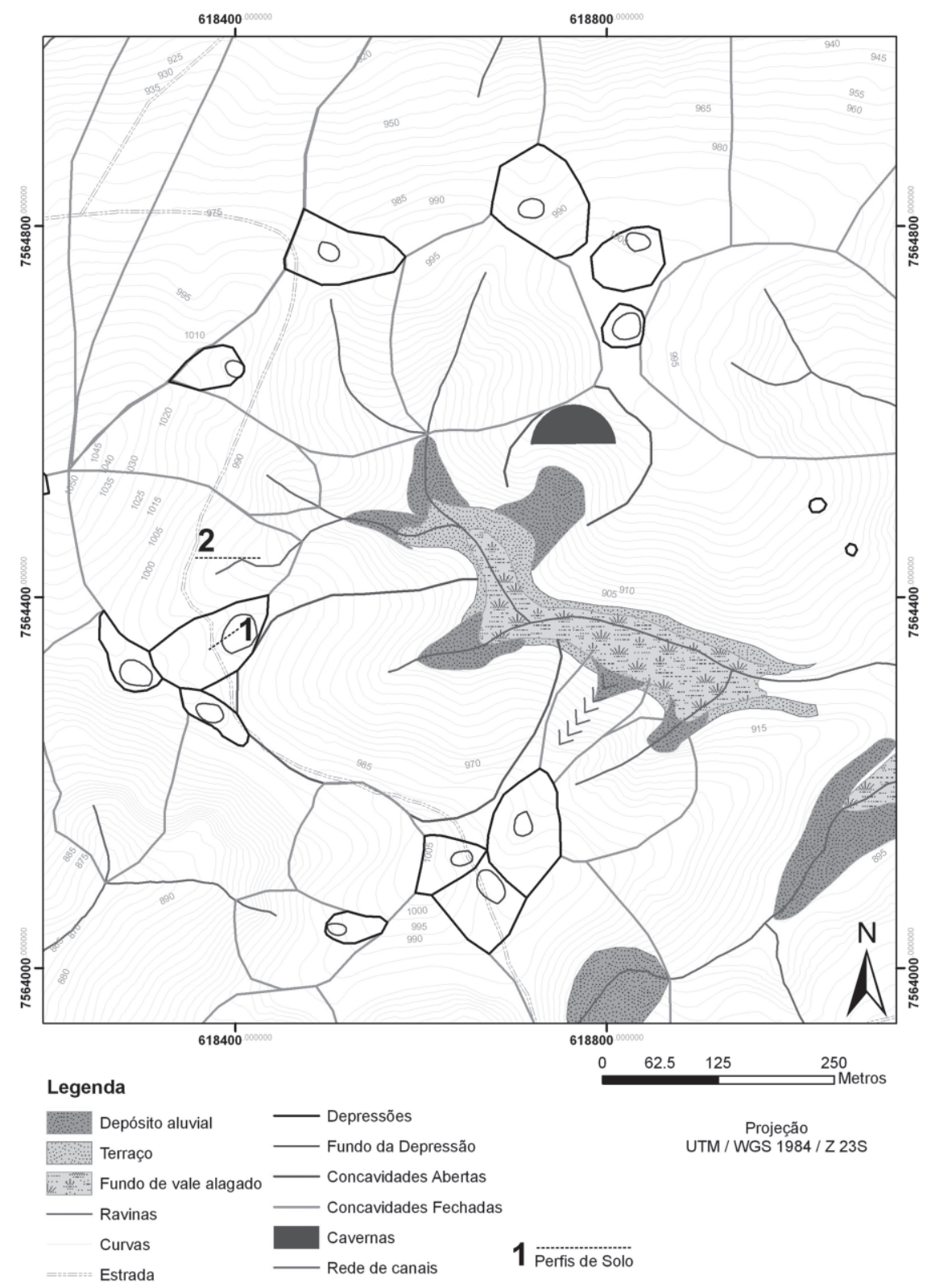

Figura 3 - Mapa de feições geomorfológicas da sub-bacia do Córrego dos Carneiros. (1) depressão selecionada com seção estratigráfica; (2) concavidade suspensa com seção estratigráfica. 


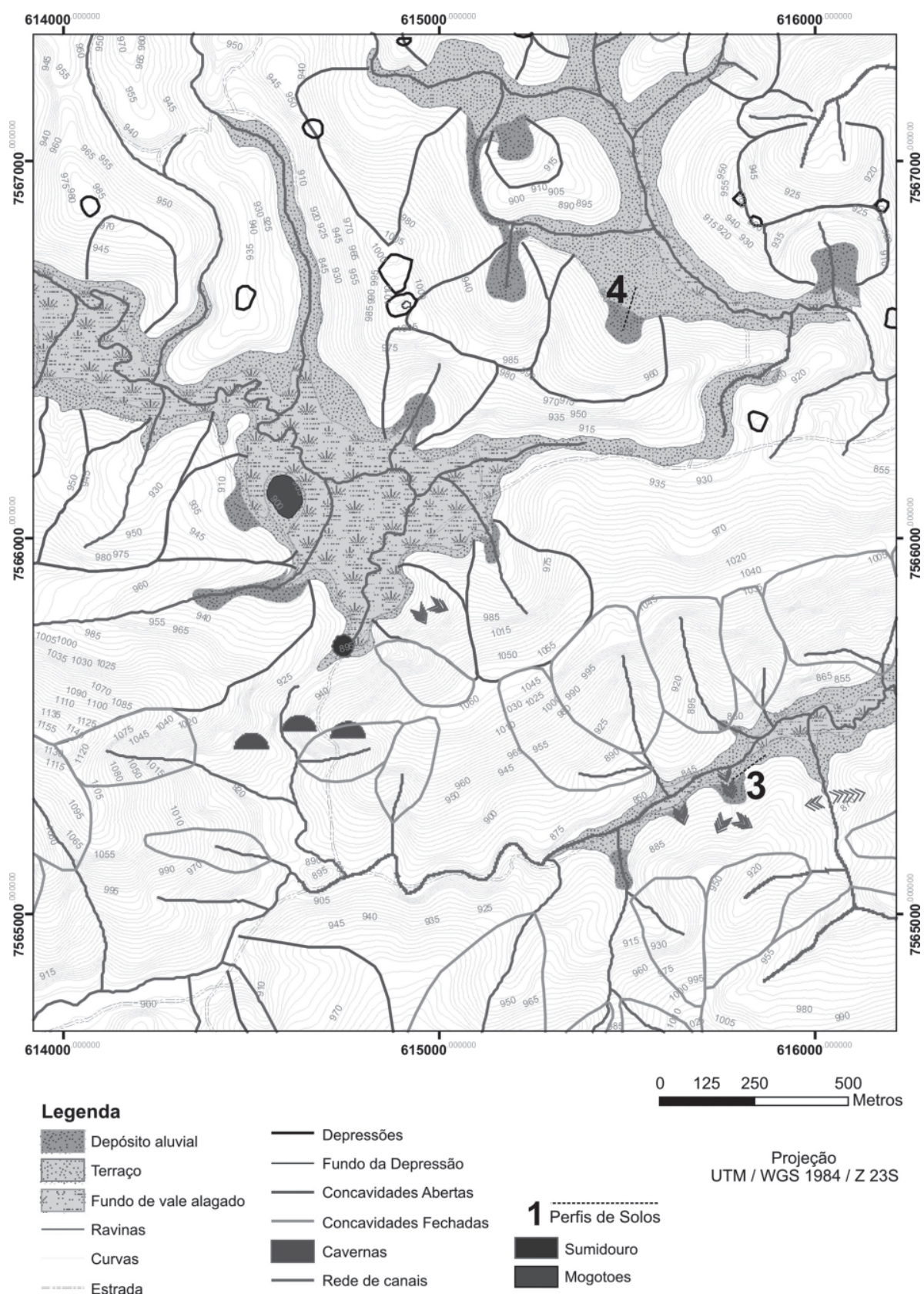

Figura 4 - Mapa de feições geomorfológicas no médio vale do Ribeirão Santana. (3) localização do perfil estratigráfico no córrego Luiza; (4) localização do perfil estratigráfico no córrego São Lourenço.

\section{Idade dos depósitos: resultados iniciais}

Os depósitos estocados no fundo das depressões, ou nas concavidades suspensas (como visto na figura 3 ) já foram descritos em Uagoda et al. (2006) e estão sendo apresentados aqui apenas para demonstrar a posição de coleta de solo para datação. No transecto da depressão pertencente ao grupo depressões rasas em encostas, na figura 5(1), foi encontrado um perfil de matéria orgânica de textura franco argilosa, com 50cm de espessura, a aproximadamente 3 metros de profundidade da superfície atual (seta). A análise de ${ }^{14} \mathrm{C}$, indicou que tal perfil possui idades entre $7830+/-95$ anos (A.P.), no topo do perfil e $8620+/-95$ anos (A.P.), na base do perfil. Em uma concavidade estrutural suspensa adjacente a esta depressão, na figura 5(2), foram coletados fragmentos de matéria orgânica no perfil indicado como de número 3 (seta), que possui textura franco arenosa. A análise de ${ }^{14} \mathrm{C}$ indicou que tal perfil possui idade de $7200+/-90$ anos (A.P.), sendo bastante próxima da idade obtida para o perfil da ma- 
téria orgânica da depressão, o que pode indicar que as duas feições tenham iniciado seu processo de formação no mesmo período, mas apenas uma delas abriu e evoluiu com a abertura do vale.

No caso dos depósitos aluviais de encostas no médio vale da bacia do ribeirão Santana, foram identificados depósitos suspensos no Ribeirão São Lourenço, na figura 6(3), e no córrego Luíza, na figura 6(4). Estes dois perfis analisados encontram-se a aproximadamente 7 metros acima da atual planície de inundação do rio imediatamente adjacente. Tais perfis já foram descritos em Uagoda et al (2006). Os depósitos de matéria orgânica do córrego Luíza estão embutidos a aproximadamente 2 metros da superfície atual e apresentam textura franco-argilosa. A análise de ${ }^{14} \mathrm{C}$ indicou que tal perfil possui idades entre $7670+/-50$ anos (A.P.) e $7780+/-50$ anos (A.P.).

Figura 5 - Perfis estratigráficos adjacentes na depressão (1) $e$ concavidade (2), na bacia do córrego dos Carneiros (ver localização na Figura 3). A seta indica o local de coleta para datação

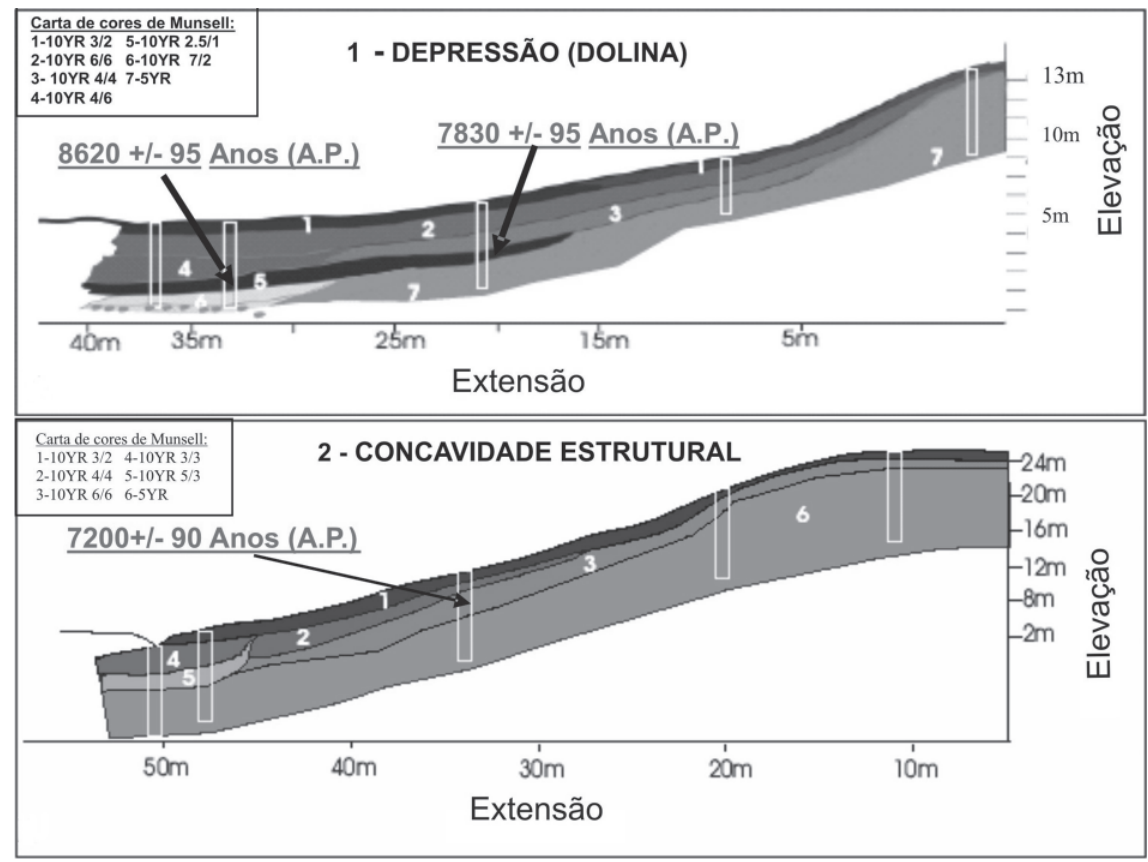

Figura 6 - Perfil estratigráfico no leque aluvial (3) que converge para o Ribeirão São Lourenço (ver localização na Figura 4) e perfil estratigráfico do leque aluvial (4) que converge para o Córrego Luiza (ver localização na Figura 4). As setas indicam os locais de coleta para datação.

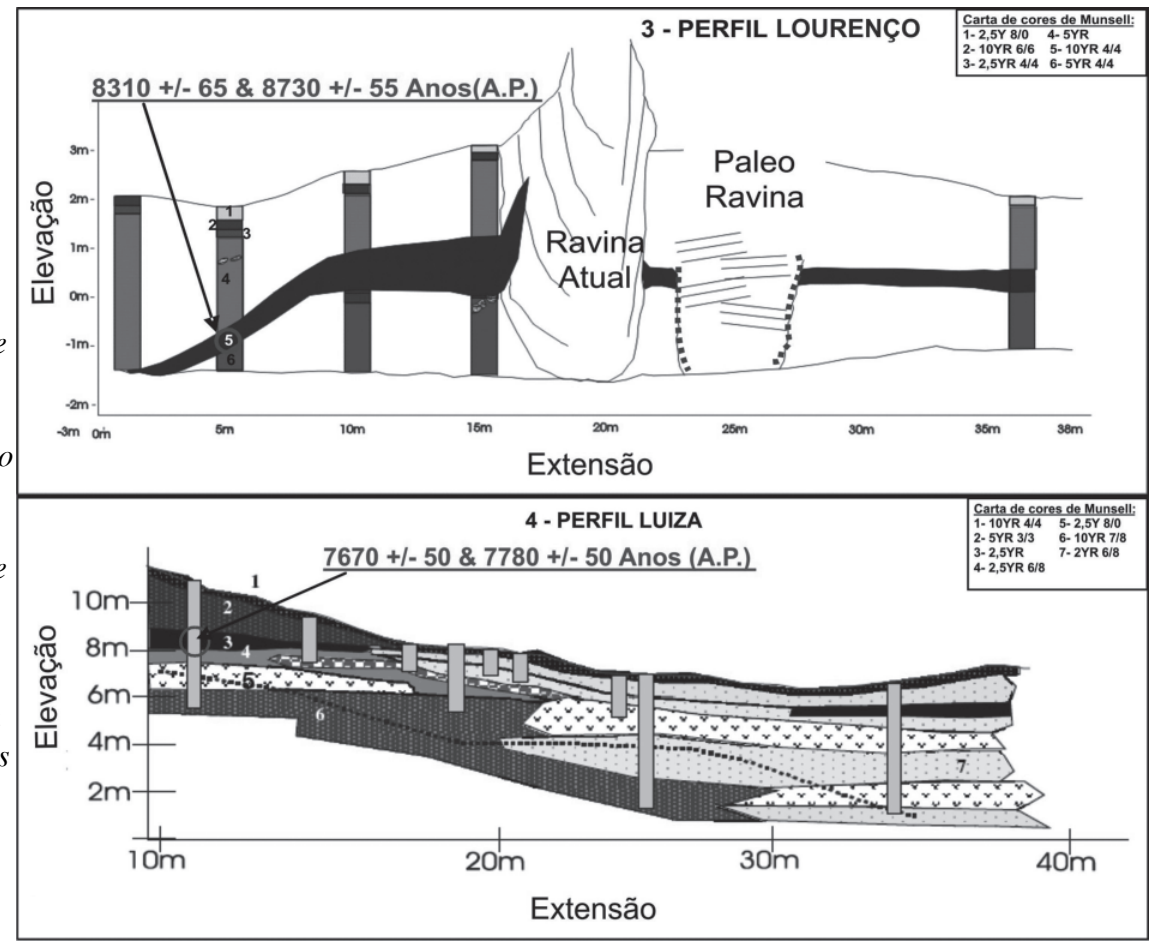


Os depósitos de matéria orgânica relativos ao córrego São Lourenço, na figura 6(3) estão embutidos entre 3 e 1,5 metros da superfície atual, possuindo textura arenosa grosseira e angulosa. A análise de ${ }^{14} \mathrm{C}$ indicou idades entre 8310 +/- 65 anos (A.P.) e 8730 +/- 55anos (A.P.). Esta seção foi descrita por Uagoda et al (2006) onde os autores mostram que esta concentração de matéria orgânica é relativa a um período de formação brejosa no fundo do vale; a presença de uma paleo-ravina dissecando esta camada orgânica revela que esta zona saturada foi bruscamente esvaziada e, posteriormente, foi preenchida novamente pela contribuição de sedimentos quartzosos da encosta à montante. Atualmente esta mesma encosta encontra-se sob processo ativo de ravinamento em reposta ao corte de uma estrada aberta recentemente.

\section{Considerações Finais}

Dos quatro grupos de depressões demarcadas, ao menos duas delas (grupo 2 e 3) aparentam ter relação direta com o processo evolutivo de abertura de concavidades topográficas em encostas, assim como trata Coelho Netto (2003). Os outros grupos (1 e 4) podem representar um estágio antecedente a interconexão de fluxos sub-superficiais. Os dados de datação absoluta corroboram tal interpretação ao demonstrar idades semelhantes entre depósitos orgânicos de depressões e concavidades adjacentes. Os depósitos identificados demarcam um evento de ruptura, aparentemente com propagação regional, deixando suspensos depósitos de encostas a cerca de 7 metros do nível atual. Tal evento pode estar relacionado à captura do Ribeirão Santana, desenvolvida pelo sumidouro mapeado. Datas mais recentes identificadas nos depósitos localizados a montante do sumidouro podem demarcar um tempo diferenciado de ajuste das formas ao novo evento erosivo, de dissecação pela ruptura. Uma ampliação da amostragem para datação, assim como uma verticalização nos estudos hidrogeoquímicos será necessária para ampliar o entendimento da evolução geomorfológica desta bacia hidrográfica.

\section{Referências Bibliográficas}

Avelar, A. S. \& Coelho Netto, A.L. (1992). Fraturas e desenvolvimento de unidades geomorfológicas côncavas no médio vale do rio Paraíba do Sul. Rev. Bras. de Geociências, 22(2).

Avelar, A. S.; Coelho Netto, A. L.; Uagoda, R. E. S. \& Ferro, C. S. R. (2006).Geologia, dissolução de rochas quartziticas e formas cársticas na bacia do ribeirão Santana (MG/ RJ). In:Simpósio Nacional De Geomorfologia 6 / Regional Conference On Geomorphology.

Castro, S.S. \& Coelho Netto, A.L. (2002). Evolução Pedogenética em Depressão de Topo na Bacia do Alto Rio Fortaleza, Região do Bananal (RJ). In: Encontro Sobre Engenharia Geotécnica E Hidrologia No Sisema Encosta-Planície Costeira, 4, Anais. P.181-192.
Coelho Netto, A.L. (2003). Evolução de cabeceiras de drenagem no médio Vale do Rio Paraíba do Sul (SP/RJ): a Formação e o crescimento da Rede de Canais sob Controle Estrutural. In: Revista Brasileira de Geomorfologia, 2: 69-100.

Dantas, M.E. (1995). Controles naturais e antropogênicos da estocagem diferencial de sedimentos fluviais: bacia do rio Bananal (SP/RJ), médio vale do rio Paraíba do Sul (Rio de Janeiro). Programa de Pós Graduação em Geografia da Universidade Federal do Rio de Janeiro. Dissertação de Mestrado. 140p.

Filizola, H. F. A \& Boulet, R. (1996). Evolution and opening of closed depressions developed in quartzkaolinitic sedimentary substratum at Taubate basin, São Paulo, Brazil, and analogy to the slope evolution. Geomorphology, 16: 77-86.

Folk R.L. \& Ward W.C. (1957). Brazos river bar: a study of significante of grain size parameters. J. Sediment. Petrol., 27:3-26.

Heilbron, M. (1995). O Segmento Central da Faixa Ribeira: síntese geológica e ensaio de evolução geotécnica. Tese de livre docência. DGEL/UERJ. 110p.

Munsell. (1971). Soil Color Charts. Munsel color company, inc. Baltimore.

Oliveira, M.A. \& Méis, M.R.M.(1985). Relações entre a geometria do relevo e formas de erosão linear acelerada (Bananal, SP), Geociências, 4, São Paulo, p. 87-99.

Ribeiro, A.; Paciullo, F. V. P; Andreis R. R.; Trouw, R. A. J. \& Heilbron, M. (1990). Evolução policíclica proterozóica no sul do Cráton do São Francisco: análise da região de São João dei Rei e Andrelândia, MG. In: congresso brasileiro de Geologia, 36, Natal, Anais, Natal, SBG, vol. 6, pg. 2605-2614.

Uagoda, R.; Avelar, A.; Coelho Netto, A.L. (2006). Contribution to carstic geomorphology in quartzitic rocks: mid preto river valley, Rio de Janeiro/Minas Gerais. In:Simpósio Nacional De Geomorfologia 6 / Regional Conference On Geomorphology.

Uagoda, R., (2006). Reconhecimento geomorfológico de relevo cárstico em rochas quartzíticas: bacia hidrográfica do Ribeirão Santana, médio vale do rio Paraíba do Sul./ Dissertação de Mestrado, PPGG-UFRJ, Rio de Janeiro.

Uagoda, R.; Avelar, A.; Coelho Netto, A.L. (2008). Karstic morphology in quartzose rocks: santana river basin at middle paraíba do sul river valley, minas gerais state/brazil. In: Australian and New Zealand Geomorphology Group, Thirteenth Conference Queenstown, Western Tasmania. 